\title{
Les chants des oiseaux. Musiques, pratiques sociales et représentations du XIe au XVIIIe siècle.
}

Rencontres interdisciplinaires et internationales

Martine Clouzot, Corinne Beck, Massimo Privitera et Vasco Zara

\section{OpenEdition}

\section{Journals}

Édition électronique

URL : https://journals.openedition.org/cem/1065

DOI : $10.4000 /$ cem. 1065

ISSN : 1954-3093

Éditeur

Centre d'études médiévales Saint-Germain d'Auxerre

Édition imprimée

Date de publication : 15 août 2007

ISSN : 1623-5770

Référence électronique

Martine Clouzot, Corinne Beck, Massimo Privitera et Vasco Zara, «Les chants des oiseaux. Musiques, pratiques sociales et représentations du Xle au XVIIIe siècle. », Bulletin du centre d'études médiévales d'Auxerre | BUCEMA [En ligne], 11 | 2007, mis en ligne le 05 octobre 2009, consulté le 22 septembre 2022. URL : http://journals.openedition.org/cem/1065 ; DOI : https://doi.org/10.4000/cem.1065

Ce document a été généré automatiquement le 22 septembre 2022.

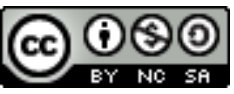

Creative Commons - Attribution - Pas d'Utilisation Commerciale - Partage dans les Mêmes Conditions 4.0 International - CC BY-NC-SA 4.0

https://creativecommons.org/licenses/by-nc-sa/4.0/ 


\section{Les chants des oiseaux. Musiques, pratiques sociales et représentations du XIe au XVIIIe siècle.}

Rencontres interdisciplinaires et internationales

Martine Clouzot, Corinne Beck, Massimo Privitera et Vasco Zara

1 Le thème du chant des oiseaux a particulièrement été bien traité par les musicologues. L'objectif de ce projet consiste à reprendre cette thématique en l'élargissant à d'autres disciplines a priori éloignées, dont les problématiques centrales touchent essentiellement aux notions de nature, de langage et de mémoire.

2 Jamais encore un projet autour d'un thème aussi étendu n'a été réalisé. L'ambition de ces rencontres interdisciplinaires et internationales vise alors à réunir les nombreux chercheurs s'étant intéressés aux « chants des oiseaux » au cours de leurs recherches.

3 Cette thématique sera traitée sur la période allant du Moyen Age au XVIIIe siècle. Les études musicologiques justifient en effet cette chronologie, mais l'objet de recherche étant commun à plusieurs disciplines, il sera intéressant, en revisitant le thème, d'observer si la période retenue est effectivement la bonne.

4 Le projet a été initié et est porté par Corinne Beck, archéo-zoologue médiéviste (UMR7041 - Paris X et Paris 1, ARSCAN, Équipe archéologies et environnements, Maison de l'Archéologie et de l'Ethnologie), Massimo Privitera, musicologue (XVe-XVIe siècles) (Université de Calabre, Cosenza), Vasco Zara, musicologue (UMR 5594 ARTeHIS Université de Bourgogne) et Martine Clouzot, historienne médiéviste (UMR 5594 ARTeHIS - Université de Bourgogne). 


\section{État des lieux}

5 L'étendue du sujet et l'éparpillement des travaux justifient amplement de réunir les différents chercheurs qui aborderont le sujet selon les objets, les sources, les méthodes, les repères chronologiques, les environnements naturels et les espaces géographiques particuliers à leur domaine de recherche et à leur période historique.

6 Le principe retenu est la mise en commun des problématiques à la fois transversales au sujet et propres à chacune des disciplines, afin de privilégier les échanges et les collaborations scientifiques entre chercheurs, entre les disciplines, entre les universités et les centres de recherches des différents pays.

\section{Présentation du sujet}

7 S'inscrivant à la croisée des sources et des regards scientifiques, ce projet cherche à mettre en présence des chercheurs issus d'horizons disciplinaires fort divers et éloignés, tant des sciences humaines et sociales que des sciences de la vie archéologues, ornithologues, éthologues, historiens, historiens de l'art, littéraires, philosophes, sémiologues et musicologues - intéressés par les différentes définitions des " chants des oiseaux ", en vue de construire un objet de recherche commun.

La réflexion pourrait s'articuler autour des questionnements suivants :

- Savoirs scientifiques et savoirs communs d'hier et d'aujourd'hui : quels oiseaux chantent et pourquoi chantent-ils ? Comment les biologistes et les ornithologues définissent-ils les « cris » des oiseaux ? Quels enseignements fournissent les recherches en éthologie ? Selon quels critères leur chant est-il considéré comme un « chant »? Quelles propriétés (physiologique, acoustique, biologique, esthétique, etc.) permettent de définir la « musique » des oiseaux? Comment les percevons-nous comme un chant?

- Du chant à la musique : quel sens chacun, en fonction de ses origines disciplinaires, donne-til au terme « chant » dès lors qu'il est rapporté aux oiseaux ? Comment établit-on le passage du chant à la musique ? Inversement comment et pourquoi les hommes intègrent-ils le chant des oiseaux dans leurs compositions musicales? Qui donne une valeur esthétique à ces chants ? Et comment cette dimension peut être perçue selon le système socio-culturel du locuteur?

- La nature, le langage et la mémoire : quels sont les rapports entre le chant naturel et le chant « appris » ? L'imitation vocale pose les questions d'une part de la perception que l'oiseau a de la voix humaine, d'autre part de ce qu'il mémorise. Comment et pourquoi l'oiseau imite-t-il les mélodies des hommes et les « bruits » de la nature ? Les oiseaux ont-ils toujours chanté la même chanson selon les régions et les époques?

- Une anthropologie des chants des oiseaux : quelles pratiques les sociétés, ou les groupes sociaux, ont-ils organisé dans le temps et dans l'espace en fonction des chants des oiseaux? Comment les hommes ont-ils exprimé par l'écrit et par la musique, figuré par l'image, façonné par les objets, leurs modes de représentations des oiseaux et de leurs chants au cours des siècles, et à quelles fins?

Un projet interdisciplinaire pour la construction d'un objet commun

$\mathrm{Du}$ fait des particularités scientifiques du thème, le projet est interdisciplinaire : du Moyen Âge à la fin du XVIIe siècle, il regroupe les travaux des archéo-zoologues, des ornithologues, des éthologues, des historiens, des historiens de l'art, des historiens de 
la littérature, des sémiologues, des zoo-sémiologues, des philosophes et des historiens de la musique, des musicologues.

11 Le projet est également international : plusieurs universités et centres de recherches européens (France, Italie, Allemagne, en l'état actuel du projet) regroupent des spécialistes de la question.

\section{Organisation du projet}

12 L'originalité du projet résidant dans sa pluridisciplinarité, il fonctionnera, non comme un colloque magistral, mais plutôt sous la forme de tables rondes de 2 à 3 jours s'échelonnant sur 3 années, successivement en France, en Italie et en Allemagne -la première devant se tenir en France.

13 Dans le but de fédérer une communauté scientifique autour d'un objet de recherche, ces tables rondes s'adressent aux chercheurs, aux universitaires et sont ouvertes aux doctorants.

14 Les résultats et les conclusions des séminaires devraient permettre d'envisager la publication des actes de ces rencontres internationales et interdisciplinaires.

15 Un programme prévisionnel en 3 étapes :

- $1^{\text {ère }}$ séance : «Les chants des oiseaux ». Présentation des sources, des approches et des concepts.

- $2^{\text {ème }}$ séance : « Musique, nature et langage »-formalisations du passage du chant au son musical et au langage, dimension esthétique du chant émis et perçu.

- $3^{\text {ème }}$ séance : « Représentations, pratiques sociales et anthropologie ».

INDEX

Mots-clés : chant des oiseaux, musique, oiseau 